\title{
Space allocation and tenant placement at high-rise shopping malls
}

Received (in revised form): 18 August 2008

\section{Chung-Yim Yiu}

is currently an assistant professor in the Department of Real Estate and Construction, the University of Hong Kong. He is a qualified building surveyor, a professional facility manager and a corporate member of the Hong Kong Institute of Surveyors, the Royal Institute of Chartered Surveyors and the American Real Estate Society. His research interests and expertise are in facility performance assessment, building maintenance, and property and construction economics and finance.

\section{Sherry Y.S. Xu}

is a student of Chung-Yim Yiu in the Department of Real Estate and Construction, the University of Hong Kong.

\section{Hing Cheong Ng}

is a research assistant to Chung-Yim Yiu in the Department of Real Estate and Construction, the University of Hong Kong.

\begin{abstract}
This paper explores the relationship among shop size (space allocation), tenant type (tenant placement) and locations of shop in a shopping mall. In contrast with previous studies, this paper tests the hypotheses empirically by means of regression models, in the context of high-rise shopping malls. The results show that bigger shops and tenants of non-impulse trades are more likely to be found at upper floors. The findings have strong practical implications for shopping mall design, and for space allocation and tenant placement strategies at shopping malls to maximise their profits.
\end{abstract}

\section{Keywords:}

shopping malls, high-rise, space allocation, tenant placement

Journal of Retail and Leisure Property (2008) 7, 315-324.

doi:10.1057/rlp.2008.22; published online 8 October 2008

\section{INTRODUCTION}

Shopping malls, famous for their huge size and variety of tenants, have

Chung-Yim Yiu

Department of Real Estate and Construction

The University of Hong Kong

Pokfulam, Hong Kong

Tel: +85228578629

Fax +85225599457

E-mail: ecyyiu@hkucc.hku.hk blossomed in many parts of the world. They have tended to be larger and larger in recent years, as shown in Table 1. There are two ways to expand their sizes: horizontally and vertically. In general, most of them expand their sizes horizontally by increasing their footprint, and the number of storeys of a shopping mall is often below six. For example, the Golden Resources Shopping Mall in Beijing, China, which opened in 2004, provides more than 1,000 shops and $560,000 \mathrm{~m}^{2}$ gross lettable area (GLA) 
Table I: World's ten largest shopping malls (in the order of Gross floor area (GFA))

\begin{tabular}{lllrr}
\hline Shopping mall & Year opened & GFA (m2) & GLA (m2) & No. of shops \\
\hline South China Mall, Dongguan, China & & & & \\
Berjaya Times Square, Kuala Lumpur, Malaysia & 2005 & 892,000 & 660,000 & 1,500 \\
Golden Resources Shopping Mall, Beijing, China & 2004 & 700,000 & 320,000 & 1,000 \\
Dubai Mall, Dubai, United Arab Emirates & $2008^{*}$ & 680,000 & 560,000 & $>1,000$ \\
West Edmonton Mall, Alberta, Canada & 1981 & 590,000 & 377,000 & 1,200 \\
Beijing Mall, Beijing, China & 2005 & 570,000 & 350,000 & 800 \\
Cevahir Istanbul, Istanbul, Turkey & 2005 & 420,000 & 320,000 & 600 \\
Zhengjia Plaza, Guangzhou, China & 2005 & 420,000 & 348,000 & 280 \\
SM Mall of Asia, Pasay City, Philippines & 2006 & 386,000 & 386,000 & 1,000 \\
SM City North Edsa, Quezon City, Philippines & 1985 & 331,800 & 270,270 & 900 \\
SM Megamall, Mandaluyong City, Philippines & 1991 & 331,600 & 324,300 & 800 \\
& & & & \\
\hline
\end{tabular}

Source:The rankings are based on statistics from Eastern Connecticut State University

*To be opened on 30 October 2008

over six floors. It is understandable why shopping malls are mostly flat and low-rise, as shoppers are generally reluctant to climb to upper floors, even though lifts and escalators are provided.

Interestingly, in some parts of the world, there is another recent trend of expanding mall size vertically. These high-rise shopping malls, which are of relatively smaller sized footprint, are much taller in height. They are more commonly found in cities of very high land price, but the question of how they prosper has seldom been studied. How to encourage shoppers to go upstairs becomes one of the most important challenges to the owners of these high-rise malls. There are at least two approaches: first, reducing the space in the upper storey and second, allocating space strategically in the shopping mall to lead shoppers' flow.

So far, there is no official definition of a high-rise shopping mall. In fact, there have been very few studies on this issue, even though the trend has been rapidly spreading in some cities. In this study, a high-rise shopping mall is defined as a shopping mall with more than seven storeys of retail area (excluding car parks and including basement levels). Table 2 shows some of the tallest shopping malls, which are mostly located in Asian countries such as Taiwan, Japan and Hong Kong.

How do they survive? What are the strategies in space allocation at these high-rise malls? These are the research questions of this paper. The aim of this study is to test empirically how landlords allocate space in high-rise shopping malls, by considering data samples from Hong Kong. It provides an economic explanation for the space allocation patterns of shops with different sizes and functions at different height levels. We put forward the following two hypotheses for empirical testing in this paper:

1. The higher floor level a shop is located at a mall, the larger floor area of the shop, ceteris paribus.

2. Shops selling impulse merchandise are located on lower storeys, ceteris paribus.

\section{LITERATURE REVIEW}

Since the 1990s, research on space allocation among shopping malls boomed as a branch of research on shopping centre leasing. Space 
Table 2: High-rise shopping malls around the world (in the order of no. of storey)

\begin{tabular}{|c|c|}
\hline Name of the shopping mall & $\begin{array}{l}\text { No. of storey* (B=basement } \\
\text { level; /F=floor level) }\end{array}$ \\
\hline Mega Box, Hong Kong & $19(\mathrm{G} / \mathrm{F}$ to $18 / \mathrm{F})$ \\
\hline Langham Place, Hong Kong & I5 (B2 to I3/F) \\
\hline Living Mall, Taiwan & I5 (B3 to I2/F) \\
\hline Times Square, Hong Kong & 15 (B2 to I3/F) \\
\hline Dream Mall, Taiwan & 12 (B2 to I0/F) \\
\hline Berjaya Time Square, Kuala Lumpur, Malaysia & II (LG/F to 9/F) \\
\hline APM, Hong Kong & II (B4 to 6/F and II/F) \\
\hline Marunouchi Building, Japan & $\mathrm{II}(\mathrm{BI}$ to $8 / \mathrm{F}$ and $35 / \mathrm{F}, 36 / \mathrm{F})$ \\
\hline New Town Plaza, Hong Kong & 10 (B2 to 8/F) \\
\hline Osaka Garden City, Japan & 9 (B2 to 7/F) \\
\hline Zhengjia Plaza, Mainland China & 9 (BI to $7 / F)$ \\
\hline TaiMall,Taiwan & 9 (B2 to 7/F) \\
\hline Shin-Marunouchi Building, Japan & 8 (BI to $7 / F)$ \\
\hline Grand Century Plaza, Hong Kong & $7(\mathrm{I} / \mathrm{F}$ to $7 / \mathrm{F})$ \\
\hline
\end{tabular}

Source: Public website of each shopping mall

*All information is based on the statistics in the end of 2007

allocation within a shopping mall refers to the way by which retail spaces are distributed to different categories of shops with the aim of sales/profit maximisation of the shopping centre. Sim (1984) posited that the optimal size of a retail shop depends on the balance between operating costs and floor space requirements. Thus, businesses such as electrical appliance shops, furniture outlets and restaurants require large floor areas to accommodate their business activities, while those selling beauty products, jewellery and watches are smaller in size but grow in number to meet the consumer demand. This model does not, however, take rent and shoppers' flow into account, which are the crux of the space allocation of a shopping mall.

Consideration of shoppers' flow in the space allocation of a shopping mall had not been well established until the works of Brueckner (1993). He demonstrated that there are both anchor and nonanchor demand externalities. Hence, mall owners can maximise their profit by allocating space to various types of tenants. Following Brueckner's line of thought, Eppli and Shilling (1993) suggested that a landlord must allocate space to a mix of shop categories to maximise total rental income. Miceli et al. (1998) further explained the phenomenon by showing that increased customer traffic can increase the mall's overall profit.

Yet, there have been very few studies on tenant placement issue as far as space allocation of a mall is concerned. The space - position relationship of retail stores has seldom been addressed in previous literature, let alone that of high-rise malls, despite the well-known relationship among shoppers' flow, tenant mix and tenant placement in practice. In light of this, this paper aims to study empirically the relationship between stores' size and their positions at height.

Tenant mix and tenant placement have long been regarded as one of the most important determinants of the success of a shopping mall. For example, Sim and Cheok (1989) contended that an appropriate tenant mix 
determines the success or failure of a shopping mall and tenant placement is always vital in influencing the shoppers' circulation. Many studies, including Dawson (1983), Abratt et al. (1985), Casazza and Spink (1985), Sim and Cheok (1989) and Alexander and Muhlebach (1990), have emphasised the importance of a tenant placement strategy in achieving a better shoppers' flow, stimulating impulse shopping, etc.

Some general principles of tenant placement strategy have been put forward, such as Casazza and Spink's (1985) and Alexander and Muhlebach's (1992) 'Mix or Match' principle. Unlike the theory of space allocation in the 1980s, their models took all the three stakeholders, namely owners, tenants and shoppers, into consideration. Brown (1992), on the other hand, placed more emphasis on the spatial relationship between anchor and nonanchor tenants, and low-impulse and highimpulse trades, ${ }^{1}$ in tenant placement strategies. For example, Brown (1992) posited that high-impulse trade should be placed nearer to areas with higher pedestrian flow. This is similar to Sim and Cheok's (1989) contention that high-impulse trades, such as boutiques, gift shops and toy shops, require high pedestrian flow and better locations to sustain their businesses.

Along this line of thought, it is plausible to hypothesise that shops of high-impulse trades and nonanchors would be allocated on lower storeys, whereas shops of low-impulse trades and anchors are on upper storeys. Thus, shops on lower storeys would be smaller in size, whereas shops on upper storeys are bigger.

\section{DATA AND METHODOLOGY}

Three high-rise shopping malls in Hong Kong are chosen for the empirical study: Langham Place (LP), Times Square (TS) and Grand Century Place (GCP). They are chosen because they are of similar scale, are located at three different prime locations of the urban developed area of Hong Kong and are old enough for appropriate tenants to settle down. General information of the three malls is summarised in Table 3, which shows that the three malls are of similar scale with about 200 shops and about $30,000 \mathrm{~m}^{2}$ GLA. LP and TS have a 15-storey design, whereas GCP has a seven-storey design.

The lettable floor area (LFA) of each shop within these three malls is measured directly from the approved general building plans, with reference to the relevant shopper guides. The current retail trade of each shop and which floor level (FL) it is located on is identified by actual site visits. Summary statistics of the data are shown in Table 4. In these 653 shops, FL ranges from -2 (basement level 2) to 13

Table 3: Summary information of the sample malls

\begin{tabular}{lccc}
\hline & LP & TS & GCP \\
\hline No. of shops & 221 & 228 & 204 \\
Total GLA $\left(\mathrm{m}^{2}\right)$ & 21,836 & 43,791 & 37,685 \\
No. of storeys & $15(-2$ to I3) & $15(-2$ to I3) & 7 (1 to 7$)$ \\
\hline
\end{tabular}


Table 4: Summary statistics of the sample shops

\begin{tabular}{lrcrc}
\hline Continuous variables & Mean & Standard deviation & Maximum & Minimum \\
\hline FL & 4.41 & 3.85 & 13 & -2 \\
LFA & 158.21 & 373.80 & 6,210 & 3 \\
LFA (at LP) & 98.81 & 170.31 & 1,129 & 3 \\
LFA (at TS) & 192.07 & 391.02 & 3,927 & 7 \\
LFA (at GCP) & 184.73 & 490.45 & 6,210 & 6 \\
\hline
\end{tabular}

No. of observations $(N)=653$

(13th Floor), and LFA ranges from $3 \mathrm{~m}^{2}$ to $6,210 \mathrm{~m}^{2}$. Figure 1 shows the distribution of the LFA of shops in these three malls.

In our sample, we found that there are two approaches to the allocation of space on upper storeys. In the first approach, the floor area of the whole storey decreases at upper storeys. In the second, the floor area of each shop increases on upper storeys. For example, Figure 2 shows a scatter plot and the best fit of the total LFAs of each storey versus FL in one of the sample shopping malls: LP. It shows a clear downward trend from FL_1 to FL_13. It reveals the first approach of reducing space in upper storeys of shopping mall in this sample case.

Besides, shop size allocation and tenant placement on different storeys can be studied by a simple regression model and a probit regression model, respectively. Equation (1) shows the regression model studying the effects of (FL), the malls (M) and the various trades of business (TB dummies) on the LFA of shop $i$ :

$$
L F A_{i}=\alpha+\beta_{1} F L_{i}+\sum_{j=1}^{m-1} \gamma_{j} M_{j i}+\sum_{k=1}^{t-1} \lambda_{k} T B_{k i}+\varepsilon_{i}
$$

where $m=3$ is the total number of malls considered and $t=16$ is the total number of the trades categorised. $\alpha, \beta, \gamma$, and $\lambda$ are coefficients to be estimated and $\varepsilon$ is the error term. One of the dummies in each group is omitted to avoid exact multicollinearity. Table 5 shows the descriptions of all the variables.

We consider the following trades as non-impulse trades: $T B_{2}$ (entertainment), $T B_{3}$ (food and beverage), $T B_{4}$ (supermarkets), $T B_{12}$ (home furnishing products), $T B_{13}$ (community services), $T B_{14}$ (personal services) and $T B_{15}$ (financial services). This is because consumers of all these trades are less likely to purchase on impulse. By means of this classification method, there are 135 shops of non-impulse trade in the three malls. Equation (2) shows the simple probit regression model studying the effects of FL on non-impulse trades $\left(T B \_N I T_{i}\right)$ of shop $i$ :

$$
\Lambda\left(T B_{-} N I T_{i}\right)=\left(\alpha^{\prime}+\beta^{\prime}{ }_{1} F L_{i}+\varepsilon^{\prime}{ }_{i}\right)
$$

where $T B_{-} N I T_{i}=T B_{2}+T B_{3}+T B_{4}+T B_{12}+T B_{13}+T B_{14}+T B_{15}$, which equals 1 if shop $i$ is non-impulse trade and 0 otherwise. $\Lambda$ represents the probit function. In these two estimations, shops below ground floor (basement levels) are not taken into consideration. 

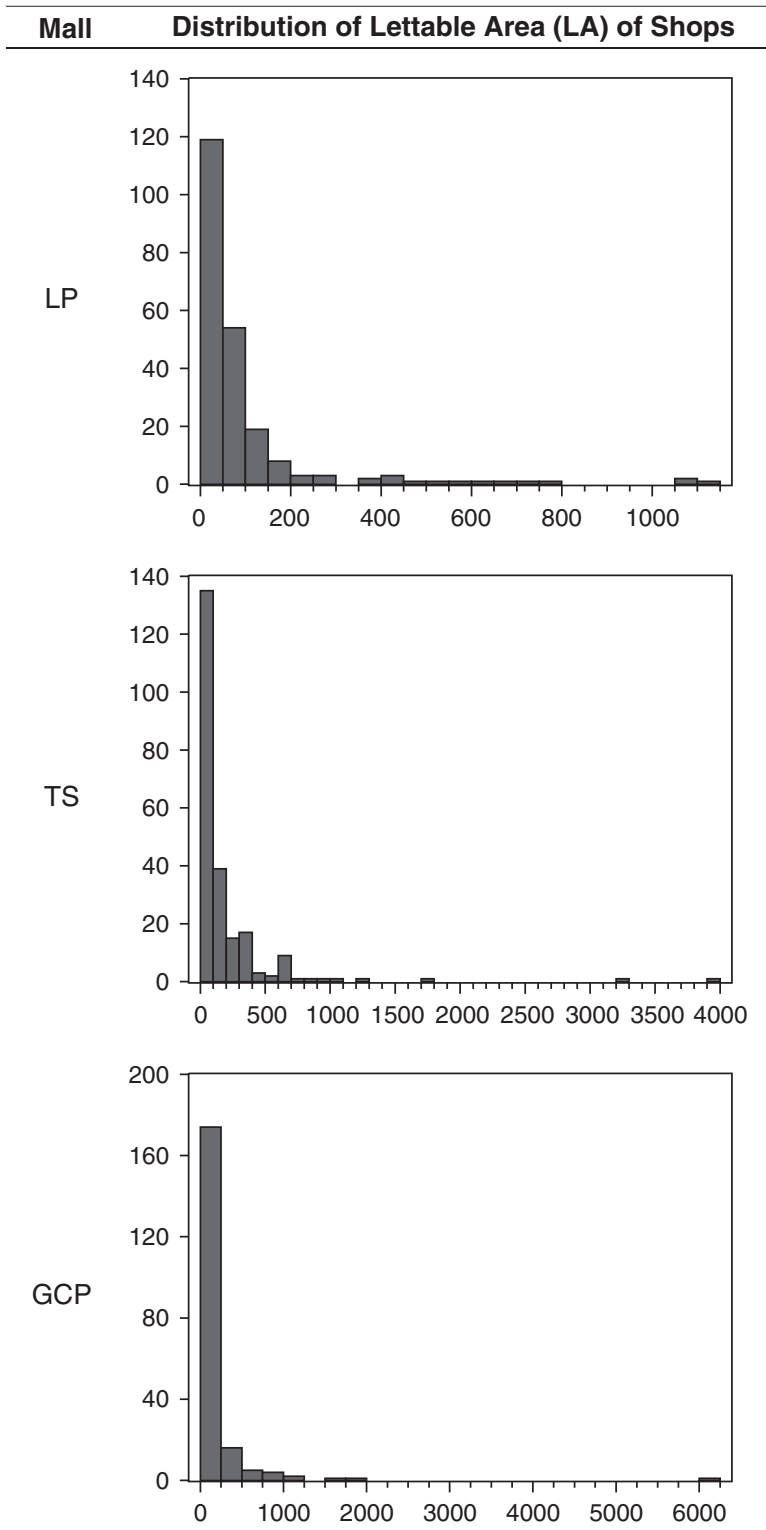

Figure I: Histograms of LFA of the three malls

\section{RESULTS}

Table 6 shows the regression results of equation (1) that FL has a positive $(\beta=9.70)$ and significant impact on the LFA of individual shop, at the ten per cent significance level. This implies that one storey higher would result in about $9 \mathrm{~m}^{2}$ more in LFA allocation of individual shops in highrise shopping malls, other things being equal. TS $\left(M_{1}\right)$ and $\operatorname{GCP}\left(M_{3}\right)$ generally have bigger shops than LP $\left(M_{2}\right)$. Department stores $\left(T B_{1}\right)$, shops for entertainment $\left(T B_{2}\right)$, food and beverage shops $\left(T B_{3}\right)$ and supermarkets $\left(T B_{4}\right)$ are found to be significantly bigger than other kinds of shops. Yet the effects of other trades are not statistically significant.

Table 7 (Panel A) shows the probit regression results of equation (2) that FL has a positive and significant impact on the shop allocation for 


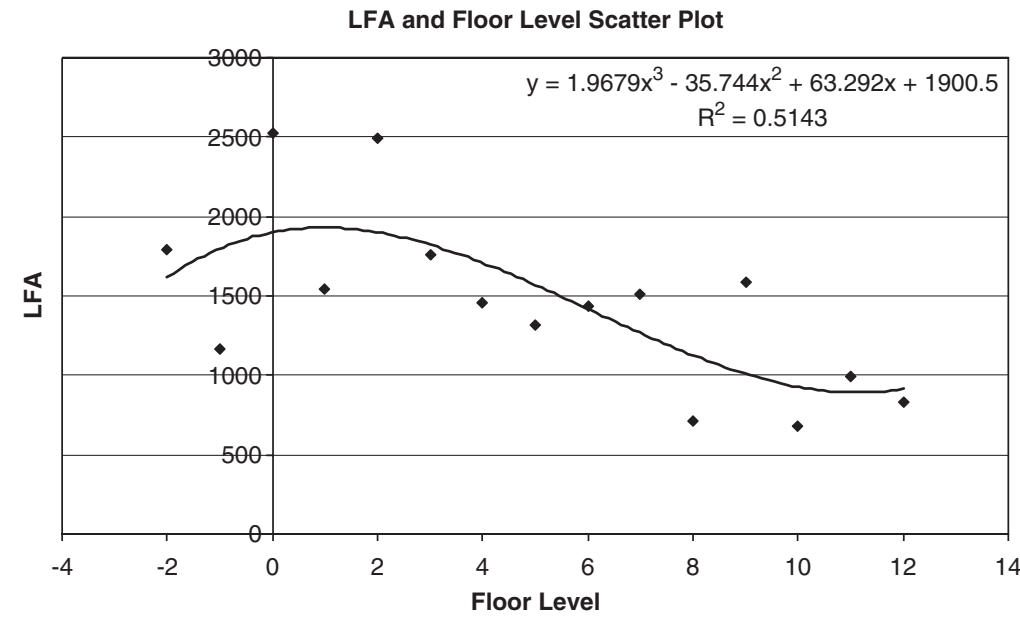

Figure 2: Scatter plot and the best fit of the total LFA of a storey plot against FL at LP

Table 5: Descriptions of the variables of equation (I)

\begin{tabular}{|c|c|}
\hline Variables & Descriptions \\
\hline \multicolumn{2}{|c|}{ Dependent variable } \\
\hline$L F A_{i}$ & Lettable floor area of the shop $i$ in the shopping mall \\
\hline \multicolumn{2}{|c|}{ Independent variables } \\
\hline$F L_{i}$ & $\begin{array}{l}\text { Floor level of the shop } i \text { in the shopping mall (ground level=I, shops below ground level } \\
\text { are not considered in this test) }\end{array}$ \\
\hline \multicolumn{2}{|l|}{ Malls (M) } \\
\hline$M_{l i}$ & $=I$ if the shop $i$ is located at Times Square (TS), 0 otherwise \\
\hline$M_{2 i}$ & $=I$ if the shop $i$ is located at Langham Place (LP), 0 otherwise \\
\hline$M_{3 i}$ & $=I$ if the shop $i$ is located at Grand Century Place (GCP), 0 otherwise \\
\hline \multicolumn{2}{|c|}{ Trade of business (TB) } \\
\hline$T B_{l i}$ & $=\mathrm{I}$ if shop $i$ is a department store (DS), 0 otherwise \\
\hline$T B_{2 i}$ & $=I$ if shop $i$ is providing entertainment $(E), 0$ otherwise \\
\hline$T B_{3 i}$ & $=I$ if shop $i$ is serving food and beverage (FB), 0 otherwise \\
\hline$T B_{4 i}$ & $=I$ if shop $i$ is a supermarket $(S), 0$ otherwise \\
\hline$T B_{5 i}$ & $=I$ if shop $i$ is selling fashion $(F), 0$ otherwise \\
\hline$T B_{6 i}$ & $=I$ if shop $i$ is selling sports wear (SW), 0 otherwise \\
\hline$T B_{7 i}$ & $=I$ if shop $i$ is selling accessories/leather/shoes/bags (LS), 0 otherwise \\
\hline$T B_{8 i}$ & $=I$ if shop $i$ is selling personal care/health/beauty products $(P C), 0$ otherwise \\
\hline$T B_{9 i}$ & $=I$ if shop $i$ is selling audio and video/electronics (AV), 0 otherwise \\
\hline$T B_{10 \mathrm{i}}$ & $=I$ if shop $i$ is selling gifts/toys (GT), 0 otherwise \\
\hline$T B_{\| / i}$ & $=I$ if shop $i$ is selling jewellery/watches $(J W), 0$ otherwise \\
\hline$T B_{12 i}$ & $=\mathrm{I}$ if shop $i$ is selling home furnishing products (HF), 0 otherwise \\
\hline$T B_{13 i}$ & $=I$ if shop $i$ is providing community services (CS), 0 otherwise \\
\hline$T B_{14 i}$ & $=I$ if shop $i$ is providing personal services (PS), 0 otherwise \\
\hline$T B_{15 i}$ & $=I$ if shop $i$ is providing financial services (FS), 0 otherwise \\
\hline$T B_{16 i}$ & $=I$ if shop $i$ is vacant (VA), 0 otherwise \\
\hline
\end{tabular}

non-impulse trades, at the one per cent significance level. That is, more non-impulse trades are found on the upper floors of shopping malls. The result confirms our hypothesis that more non-impulse trades are allocated to upper storeys. Estimating the probability of having a shop of nonimpulse trade on a certain floor level of a mall, Panel B of Table 7 reveals that two of the malls (TS and GCP) obtained highly significant and 
Table 6: Estimation results of equation (I)

\begin{tabular}{|c|c|c|c|c|}
\hline \multicolumn{5}{|c|}{$\begin{array}{l}\text { Dependent variable: LFA } \\
\text { Method: Least squares } \\
\text { Sample: I,653 IF FL>0 } \\
\text { Included observations: } 569\end{array}$} \\
\hline Variable & Coefficient & Std. error & $t$-Statistic & Prob. \\
\hline C & 10.1766 & 69.0794 & 0.1473 & 0.8829 \\
\hline $\mathrm{FL}$ & 9.7011 & 5.5834 & 1.7375 & 0.0829 \\
\hline MI (TS) & 94.9646 & 35.7053 & 2.6597 & 0.0080 \\
\hline M3 (GCP) & 120.9038 & 40.4328 & 2.9902 & 0.0029 \\
\hline TBI (DS) & 1185.6500 & 126.3867 & 9.3811 & 0.0000 \\
\hline TB2 (E) & 378.0738 & 93.2116 & 4.0561 & 0.0001 \\
\hline TB3 (FB) & 165.8295 & 64.1090 & 2.5867 & 0.0099 \\
\hline TB4 (S) & 767.7133 & 326.2949 & 2.3528 & 0.0190 \\
\hline TB5 (F) & -3.9701 & 59.7609 & -0.0664 & 0.9471 \\
\hline TB6 (ALS) & -63.4828 & 66.8023 & -0.9503 & 0.3424 \\
\hline TB7 (AVE) & -36.6355 & 87.2259 & -0.4200 & 0.6746 \\
\hline TB8 (GCWT) & -84.0246 & 73.0648 & -1.1500 & 0.2506 \\
\hline TB9 (HF) & -47.5916 & 98.7109 & -0.4821 & 0.6299 \\
\hline TBIO (JW) & -91.6443 & 81.1013 & -1.1300 & 0.2590 \\
\hline TBII (PCHB) & -44.9914 & 71.9140 & -0.6256 & 0.5318 \\
\hline TBI2 (PS) & -53.8497 & 169.2100 & -0.3182 & 0.7504 \\
\hline TB। 3 (FS) & -43.4843 & $169.773 \mid$ & -0.2561 & 0.7979 \\
\hline TBI4 (CS) & 51.1224 & 327.0988 & 0.1563 & 0.8759 \\
\hline TBI5 (VAC) & $-74.986 I$ & 87.8318 & -0.8537 & 0.3936 \\
\hline$R^{2}$ & 0.2520 & Mean dependent var. & & 163.5193 \\
\hline Adjusted $R^{2}$ & 0.2275 & SD dependent var. & & 364.4596 \\
\hline SE of regression & 320.3349 & Akaike info criterion & & 14.4094 \\
\hline Sum squared resid. & $56,437,96$ & Schwarz criterion & & 14.5545 \\
\hline Log likelihood & $-4,080.48$ & $F$-statistic & & 10.2920 \\
\hline Durbin-Watson stat. & 1.2242 & $\operatorname{Prob}(F$-statistic) & & 0.0000 \\
\hline
\end{tabular}

positive results, with coefficient at above 0.3 , but that another mall (LP) obtained positive but statistically insignificant results, which is probably because this mall has already reduced substantially the LFA of its upper storeys, as shown in Figure 2 above, and is therefore under less pressure to place non-impulse trade tenants on the upper floors.

Table 8 extracts the summary information of the biggest 15 shops in the data sample, and it can be seen that most of them are located on upper storeys and are anchor tenants. For example, eight of them are located on or above the fifth floor and are providing entertainment, food and beverage or supermarket services. The exceptions are department stores, which are mostly located on lower storeys. Furthermore, LP has the fewest big shops, which agrees with the above finding that LP adopts the design of reducing floor area on upper storeys.

\section{CONCLUSIONS}

Shopping malls are becoming bigger and higher, but how to encourage shoppers to go to upper levels is a big issue for owners of shopping malls. Although lifts and escalators have been provided, studies show that shoppers are reluctant to go higher. If successful strategies can be found, they could have strong practical implications on the retail industry. In this study, we found empirically that both space allocation and tenant 
Table 7: Estimation results of equation (2)

\begin{tabular}{|c|c|c|c|c|}
\hline \multicolumn{5}{|c|}{$\begin{array}{l}\text { Dependent variable:TB_NIT } \\
\text { Method: ML — Binary probit (Quadratic hill climbing) }\end{array}$} \\
\hline \multicolumn{5}{|c|}{ Panel A - Combined sample } \\
\hline \multicolumn{5}{|c|}{ Sample: I,653 IF FL>0 } \\
\hline \multicolumn{5}{|c|}{ Included observations: 569} \\
\hline \multicolumn{5}{|c|}{ Convergence achieved after three iterations } \\
\hline \multicolumn{5}{|c|}{ Covariance matrix computed using second derivatives } \\
\hline Variable & Coefficient & Std. error & z-Statistic & Prob. \\
\hline C & -0.9962 & 0.1130 & $-8.8 \mid 47$ & 0.0000 \\
\hline $\mathrm{FL}$ & 0.0494 & 0.0168 & 2.9362 & 0.0033 \\
\hline Mean dependent var. & 0.2373 & SD dependent var. & & 0.4258 \\
\hline SE of regression & 0.4223 & Akaike info criterion & & 1.0876 \\
\hline Sum squared resid. & 101.0960 & Schwarz criterion & & 1.1028 \\
\hline Log likelihood & -307.4089 & Hannan-Quinn criterio & & 1.0935 \\
\hline Restr. log likelihood & -311.7545 & Avg. log likelihood & & -0.5403 \\
\hline LR statistic (I df) & 8.6912 & McFadden $R^{2}$ & & 0.0139 \\
\hline Probability(LR stat) & 0.0032 & & & \\
\hline Obs. with Dep $=0$ & 434 & Total obs. & & 569 \\
\hline Obs. with Dep=I & 135 & & & \\
\hline \multicolumn{5}{|c|}{ Panel B - Individual mall } \\
\hline Shopping mall & $\begin{array}{l}\text { No. of shops of } \\
\text { non-impulse trade }\end{array}$ & $\begin{array}{l}\text { No. of shops of } \\
\text { impulse trade }\end{array}$ & Coefficient of FL & Prob. \\
\hline MI (TS) & 26 & 155 & 0.3201 & 0.0000 \\
\hline M2 (LP) & 45 & 139 & 0.0094 & 0.7316 \\
\hline M3 (GCP) & 64 & 140 & 0.3905 & 0.0000 \\
\hline
\end{tabular}

Table 8: Summary information of the biggest I5 shops in the sample (in the order of LFA)

\begin{tabular}{llll}
\hline LFA in $\mathbf{~} \mathbf{2}$ & FL & Mall & Trade of business \\
\hline 937 & 8 & TS & \\
950 & 5 & GCP & Sports wear \\
957 & 6 & GCP & Entertainment \\
1,075 & 10 & LP & Supermarket \\
$1,079.3$ & 3 & GCP & Entertainment \\
1,088 & I & LP & Dept. store \\
1,094 & II & TS & Fashion \\
1,129 & 8 & LP & Food and beverage \\
$1,139.3$ & 3 & GCP & Entertainment \\
1,238 & 3 & TS & Entertainment \\
$1,518.9$ & 6 & GCP & Entertainment \\
1,740 & TS & TS & Food and beverage \\
$1,963.1$ & 2 & GCP & Dept. store \\
3,254 & 2 & TS & Dept. store \\
6,210 & 7 & GCP & Dept. store \\
& & & Food and beverage \\
\hline
\end{tabular}

placement strategies have been employed to deal with this dilemma. First, the LFA of shops is found to be increasing on upper storeys. Secondly, shops of non-impulse trade are more likely to be found on upper storeys. The empirical results of three large-scale and successful shopping malls in Hong Kong show significantly that shop size increases by about $9 \mathrm{~m}^{2}$ 
for each storey up, and the probability of finding shops of non-impulse trade increases on upper storeys.

The results of this study on tenant placement and space allocation strategies disagreed with Hillier's (1996, p. 161) hypothesis and Fong's (2003) configuration study that proposes that '(shoppers') movement is determined by the urban grid (configuration of the shopping mall) itself rather than by the specific attractors or magnets'. As shown in the findings of this study, successful malls are nowadays built to over ten storeys high and shoppers' movements can be stimulated by tenant placement and space allocation strategies. Our results show that these malls allocate bigger shops and non-impulse trade tenants at upper floors, so as to encourage more shoppers to go to higher storeys. This finding opens a new dimension for shopping mall design and profit maximisation tactics in retail development. The results may also shed light on how to improve shoppers' flow at low-rise shopping malls.

\section{Acknowledgements}

The work described in this paper was supported by the HKU Seed Funding Basic Research Grant of the University of Hong Kong (Project No.: 200611159026). We also thank a student, Mr W.T. Tang, for his assistance with this study.

\section{Note}

1 Nelson (1958) stated that low-impulse trades are of high-planned demand and are 'generative' business that customers can demand to buy from the shops in advance.

\section{References}

Abratt, R., Fourie, J.L.C. \& Pitt, L.F. (1985). Tenant mix: The key to a successful shopping center. Quarterly Review of Marketing. 10(3), 19-26.

Alexander, A.A. \& Muhlebach, R.F. (1990). Managing and Leasing Commercial Properties, Wiley, Canada.

Alexander, A.A. \& Muhlebach, R.F. (1992). Shopping Center Management, Institute of Real Estate Management, USA.

Brown, S. (1992). Tenant mix, tenant placement and shopper behavior in a planned shopping center. Services Industries Journal. 12(3), 384-403.

Brueckner, J. (1993). Inter-store externalities and space allocation in shopping centers. Journal of Real Estate Finance and Economics. 7, 5-16.

Casazza, J.A. \& Spink, F.H. (1985). Shopping Center Development Handbook, 2nd edn, Urban Land Institute, Washington, US.

Dawson, J.A. (1983). Topics in Applied Geography: Shopping Center Development, Longman Group Ltd, London.

Eppli, M. \& Shilling, J.D. (1993). What's a shopping center worth? Proceedings of the 1993 American Real Estate Society Conference (unpublished).

Fong, P. (2003). What makes big dumb bells a mega shopping mall? Proceedings of the 4th International Space Syntax Symposium, London, UK, http://www.spacesyntax.net/symposia/ SSS4/fullpapers/10Fongpaper.pdf.

Hillier, B. (1996). Space is the Machine, Cambridge University Press, Cambridge, UK.

Miceli, T.J., Sirmans, C.F. \& Stake, D. (1998). Optimal competition and allocation of space in shopping centers. Journal of Real Estate Research. 16, 113-126.

Nelson, R.L. (1958). The Selection of Retail Location, F.W. Dodge Corporation, New York.

Sim, L.L. (1984). A Study of Planned Shopping Centers in Singapore, Singapore University Press, Singapore.

Sim, L.L. \& Cheok, R.W. (1989). Tenant placement in a Singapore shopping center. International Journal of Retailing. 4(3), 4-16. 